\title{
Serum proteomic analysis of melanoma patients with immunohistochemical profiling of primary melanomas and cultured cells: Pilot study
}

\author{
JAN KUČERA ${ }^{1,2^{*}}$, KAROLÍNA STRNADOVÁ ${ }^{2,3^{*}}$, BARBORA DVOŘÁNKOVÁ $^{2,3}$, LUKÁŠ LACINA $^{1-3}$, \\ IVANA KRAJSOVÁ ${ }^{1}$, JIŘÍ ŠTORK ${ }^{1}$, HANA KOVÁŘOVÁ ${ }^{4}$, HELENA KUPCOVÁ SKALNÍKOVÁ ${ }^{4}$, \\ PETR VODIČKA ${ }^{4}$, JAN MOTLÍK $^{4}$, PAVEL DUNDR ${ }^{5}$, KAREL SMETANA Jr $^{2,3}$ and ONDŘEJ KODET ${ }^{1-3}$ \\ ${ }^{1}$ Department of Dermatovenereology, 1 st Faculty of Medicine and General University Hospital; \\ ${ }^{2}$ Institute of Anatomy, 1st Faculty of Medicine, Charles University, Prague 128 00; ${ }^{3}$ BIOCEV-Biotechnology \\ and Biomedical Centre of The Czech Academy of Sciences and Charles University, 1st Faculty of Medicine, \\ Charles University, Vestec $25250 ;{ }^{4}$ Laboratory of Applied Proteome Analyses and Research Centre PIGMOD, \\ Institute of Animal Physiology and Genetics, Czech Academy of Sciences, Liběchov 277 21; \\ ${ }^{5}$ Institute of Pathology, 1st Faculty of Medicine, Charles University, Prague 128 00, Czech Republic
}

Received April 14, 2019; Accepted August 7, 2019

DOI: $10.3892 /$ or.2019.7319

\begin{abstract}
The steadily increasing incidence of malignant melanoma (MM) and its aggressive behaviour makes this tumour an attractive cancer research topic. The tumour microenvironment is being increasingly recognised as a key factor in cancer biology, with an impact on proliferation, invasion, angiogenesis and metastatic spread, as well as acquired therapy resistance. Multiple bioactive molecules playing cooperative roles promote the chronic inflammatory milieu in tumours, making inflammation a hallmark of cancer. This specific inflammatory setting is evident in the affected tissue. However, certain mediators can leak into the systemic circulation and affect the whole organism. The present study analysed the complex inflammatory response in the sera of patients with MM of various stages. Multiplexed proteomic analysis (Luminex Corporation) of 31 serum proteins was employed. These targets were observed in immunohistochemical profiles of primary tumours from the same patients. Furthermore, these proteins were analysed in MM cell lines and the principal cell population of the melanoma microenvironment, cancer-associated fibroblasts. Growth
\end{abstract}

Correspondence to: Dr Ondřej Kodet, Department of Dermatovenereology, 1st Faculty of Medicine and General University Hospital, Charles University, U Nemocnice 499/2, Prague 128 00, Czech Republic

E-mail: ondrej.kodet@lf1.cuni.cz

${ }^{*}$ Contributed equally

Key words: melanoma, inflammation, microenvironment, cancerassociated fibroblasts, interleukin, proteomics factors such as hepatocyte growth factor, granulocyte-colony stimulating factor and vascular endothelial growth factor, chemokines RANTES and interleukin (IL)-8, and cytokines IL-6, interferon- $\alpha$ and IL-1 receptor antagonist significantly differed in these patients compared with the healthy controls. Taken together, the results presented here depict the inflammatory landscape that is altered in melanoma patients, and highlight potentially relevant targets for therapy improvement.

\section{Introduction}

Cancer incidence is increasing worldwide (1). Malignant melanoma (MM) incidence, as well as mortality, follows this trend in almost all countries (2). MM is an aggressive skin tumour arising from melanocytes, cells involved in the protection of skin against UV-induced damage, including the genotoxic effect of irradiation on epidermal cells.

Once metastasised, MM frequently remains a fatal neoplasm with limited therapeutic options and relatively poor outcomes. There has been notable progress, predominantly in immunomodulatory therapy, in recent years, but the therapeutic response is difficult to predict (2). However, immune checkpoint-oriented therapy is also associated with a rapid increase in disease-specific healthcare costs (3).

Therefore, there is an urgent need to identify and validate informative biomarkers to improve the early selection of at-risk patients suitable for adjuvant therapy, the optimal drug choice, and possibly for disease progress monitoring $(3,4)$.

Prognostically essential features of primary melanoma are well known and include tumour thickness [measured in $\mathrm{mm}$ according to Breslow staging (5)] and the presence of surface epidermal ulceration (6). These parameters are easily acquired by histologists in routine haematoxylin-eosin-stained paraffin sections and are indispensable prognostic factors in melanoma staging (6). More recently, biomarkers obtained after 
immunohistochemical and molecular analysis of the tumour tissue have played a critical role in melanoma management; namely, the presence of BRAF, GTPase NRas and c-KIT mutations is predictive of response to small drug inhibitors $(2,7)$. At present, no ideal biomarker predicting the therapeutic response in melanoma patients treated with other modern drugs, such as immune checkpoint modulators (e.g. anti-programmed cell death protein 1 or anti-cytotoxic $\mathrm{T}$ lymphocyte protein 4), exists (4).

In all the aforementioned cases, an invasive surgical procedure (radical excision or limited biopsy) to acquire a tissue sample is necessary.

From the perspective of a clinical oncologist, biomarkers determined from a peripheral blood sample would be extremely beneficial for a patient's regular follow-up. In case of MM, the detected molecules could include (but not be limited to) soluble proteins, melanin synthesis-related metabolites, circulating nucleic acids and/or circulating tumour cells $(4,8)$.

In the American Joint Committee on Cancer (8th edition) staging system (6), serum lactate dehydrogenase (LDH) is the only serum biomarker that is accepted as a robust prognostic parameter for routine clinical use in melanoma patients (6). Unfortunately, LDH is not a melanoma-specific enzyme, and increased LDH is also associated with many other benign and malignant diseases (9). By contrast, the S100B protein is highly specific, and its increased levels are detected in patients with advanced melanoma. Thus, the S100B protein has a strong association with melanoma prognosis (10). Notably, the European Society of Medical Oncology, German and Swiss guidelines recommend serum S100B as the most accurate serological test for follow-up, having better specificity for progressive disease compared with LDH (11-13). However, the S100 protein did not prove to be sufficient (concerning sensitivity) for detecting tumour progression, and it cannot substitute for imaging methods [e.g. computed tomography (CT) or positron emission tomography/CT] in long-term follow-up. A plethora of other biomarkers has been advocated in the literature for MM; none of these have been broadly accepted for use in a clinical setting $(6,8)$.

A limited percentage of cells released from a primary tumour are capable of colonising a new site. This phenomenon highlights the importance of a permissive tissue microenvironment during cancer progression and metastatic spread. This phenomenon was predicted in 1889 by Paget (14), who hypothesised that metastasis does not occur at particular body sites randomly. Cancer represents a complicated ecosystem of tumour cells and a variety of other cell types that form the tumour stroma, such as cancer-associated fibroblasts (CAFs), tumour-infiltrating leukocytes (TILs), pericytes and endothelial cells (15).

The microenvironment modifies critical aspects of tumour biology, such as tumour growth, local aggressiveness, lymphatic and metastatic spread, and resistance to therapy (16). The role of the microenvironment in MM biology has been documented at multiple levels. CAFs increase tumour cell plasticity and facilitate the maintenance of the undifferentiated status of tumour cells (17). CAFs can play a significant role in the mechanism of primary resistance to targeted therapy via the production of transforming growth factor- $\beta$ (18). CAFs and other stromal cells can produce several other factors with a similar effect, such as hepatocyte growth factor (HGF), which stimulates the c-Met/PI3K/Akt signalling pathway. These factors can activate tumour cell growth in a paracrine manner, thus conferring resistance to targeted therapy (19). It is evident that the cancer microenvironment is crucial for MM growth and metastatic spread, as well as for the emergence of acquired drug resistance.

It was documented recently (20) that even a minimal number of circulating tumour cells elicit a systemic inflammatory status contributing to the promotion of tumour metastasis. These circulating tumour cells represent a clinically undetectable disease burden.

On the other hand, a recent study also demonstrated that the majority of circulating tumour cells are unable to establish a proliferatively successful metastatic clone (21). This raises several important questions regarding the timing of therapeutic intervention in cancer, including MM. It seems likely that the systemic proinflammatory response could increase the risk of consequent melanoma progression to metastatic disease, resulting in shorter survival of patients. Data describing the complexity of the inflammatory landscape in $\mathrm{MM}$ are limited (22). Thus, it may only be hypothesised whether therapeutic inhibition of the inflammatory response may reduce the production of cytokines contributing to the formation of premetastatic niches suitable for disease dissemination in an organism. A better understanding of the fundamental components of this inflammatory response may be important in the design of a therapeutic strategy to prevent tumour metastasis. More research on the tumour-associated systemic inflammation blockade may reveal optimal targets to prevent and treat tumour metastasis.

The present pilot study focused on comparative multiplex analysis of 31 serum proteins from 12 patients at the time of melanoma diagnosis, and during the early onset of disease, progression using Luminex technology (Luminex Corporation). It was hypothesised that the levels of these proteins could serve as biomarkers associated with the clinical progression and pathological features of the disease. These data were also compared with the immunohistochemical profiles of selected proteins in primary tumours from the same patients. MM cell lines and a model of their microenvironment in vitro, using melanoma-specific CAFs, were also tested.

\section{Materials and methods}

Patients. MM patients $(n=12)$ and healthy volunteers $(n=5)$ participated in the study after giving explicit written consent. The study was approved by the local ethics committee (Ethics Committee of the General University Hospital, Prague; no. 15/15). All tissue and blood samples were obtained strictly with the explicit informed consent of participants of the study. Samples from MM patients and healthy volunteers were collected between May 2014 and February 2015.

The patients were diagnosed with MM based on the clinical appearance of the skin lesion. Histopathological analysis verified the diagnosis of primary cutaneous MM after tumour excision. No patient had clinical evidence of metastatic disease at the time of diagnosis. Based on this favourable status, clinical follow-up was initiated. Despite radical surgery, some patients developed metastasis during the follow-up period. The 
patient cohort characteristics are summarised in Table I. The healthy volunteers were three men (35, 40 and 66 years old), and two women (26 and 63 years old) without any evidence of cancer or chronic disease.

Cells. The BLM cell line was kindly provided by Dr L. van Kempen and Professor J.H.J.M. van Krieken (Department of Pathology, Radboud University, Nijmegen Medical Centre, Netherlands). The commercially available A2058 cell line and HP-Mel (HEMn) cell line was purchased from the American Type Culture Collection (ATCC ${ }^{\circledR}$ CRL-11147 ${ }^{\mathrm{TM}}$ and ATCC ${ }^{\circledR}$ PCS-200-012 ${ }^{\mathrm{TM}}$, respectively). MP17 melanoma cells were isolated (February 20th, 2015) from pleural ascitic fluid from a patient (74-year-old man) with tumour generalisation (Tumor-Node-Metastasis stage IV) using a previously described method (17). Culture conditions were as described in a previous study (23).

Normal primary dermal fibroblasts (acquired after breast reduction surgery, designated as HFP4 (from a 55-year-old female; localisation, chest; collected May 19th. 2014) and CAFs [two independent isolates designated as MAM (69-year-old female; localisation, chest; collected July 14th, 2014) and ZAM (48-year-old male; localisation, abdomen; collected September 9th, 2014)] from skin metastases of MM were prepared and cultured as previously described (24-26).

MP17, HFP4, MAM and ZAM cells were obtained and maintained with the informed consent of patients and the approval of the local ethical committee as indicated above. The authors confirm that mycoplasma testing was performed on all cell lines used in the present study.

Serum preparation. Venous blood was collected from MM patients $(\mathrm{n}=12)$ at three time intervals: i) At the time of diagnosis prior to any surgical treatment; ii) 1 month after the surgery; and iii) $\sim 3$ months after the surgery. The blood was left to clot for 30-60 $\mathrm{min}$ at room temperature followed by centrifugation $\left(1,500 \mathrm{x} \mathrm{g} ; 10 \mathrm{~min} ; 4^{\circ} \mathrm{C}\right)$. The obtained serum was immediately aliquoted to avoid later multiple freeze-thaw cycles and stored at $-80^{\circ} \mathrm{C}$. Control sera were obtained from healthy individuals $(\mathrm{n}=5)$ under identical conditions.

Analysis of serum samples. The levels of 31 cytokines, chemokines and growth factors were analysed using Luminex $\mathrm{xMAP}^{\circledR}$ bead assays (Luminex Corporation) in the serum of MM patients and controls. The Human Cytokine Magnetic 30-Plex Panel (Thermo Fisher Scientific, Inc.) and CXCL1 Human ProcartaPlex ${ }^{\mathrm{TM}}$ Simplex kit (Thermo Fisher Scientific, Inc.) were used to quantify epidermal growth factor (EGF), eotaxin, basic fibroblast growth factor, granulocyte-colony stimulating factor (G-CSF), granulocyte-macrophage colony-stimulating factor (GM-CSF), growth regulated- $\alpha$ protein (also known as CXCL1), hepatocyte growth factor (HGF), interferon (IFN)- $\alpha$, IFN- $\gamma$, interleukin (IL)-1 $\beta$, IL-1 receptor antagonist (IL-1RA), IL-2, IL-2 receptor, IL-4, IL-5, IL-6, IL-7, IL-8, IL-10, IL-12 (p40/p70), IL-13, IL-15, IL-17, IP-10, C-C motif chemokine 1, MIG, C-C motif chemokine 3, C-C motif chemokine 4 (MIP-1ß), RANTES, tumour necrosis factor- $\alpha$ and vascular endothelial growth factor (VEGF) levels. The manufacturer validated all antibodies used for this experiment.

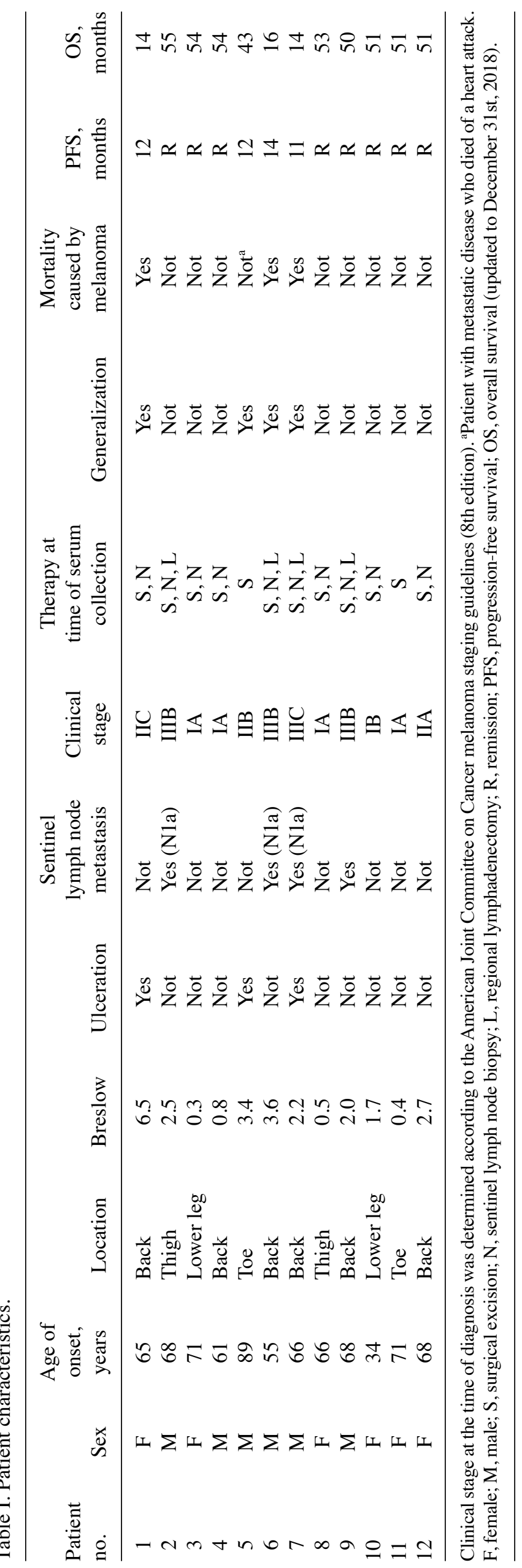


After thawing on ice, the serum samples were gently mixed, pre-cleaned via centrifugation $(16,000 \mathrm{x} \mathrm{g} ; 10 \mathrm{~min}$; $4^{\circ} \mathrm{C}$ ), and diluted at a 1:1 ratio with Assay Diluent (in the case of the 30-plex assay) or Universal Assay Buffer (in the case of the Simplex assay) to minimize the matrix effects. The same diluent buffer was used as a blank and as a diluent for the calibration standards. The calibration curve was extended at the lower end by additional dilutions of calibration standards. Reverse pipetting was used for high accuracy in all liquid handling steps. All samples, standards and background were analysed in duplicate. The assay was performed according to the manufacturer's instructions. The fluorescence intensities of minimum 100 beads/analyte were recorded using a Luminex $200^{\mathrm{TM}}$ analyser with xPonent software build 3.1.871.0 (Luminex Corporation), adequately calibrated according to the manufacturer's instructions.

Raw data were exported from xPonent software in. csv format and processed in the R statistical environment (27) using the drLumi package (28). The median fluorescence intensity was used for standard curve fitting and quantitation of cytokine concentrations. Standard curves were fitted using 5-parameter logistic regression (SSL5) with 4-parameter logistic regression as a fall-back for occasions where the SSL5 model would not converge. The concentrations of two technical replicates of each sample were averaged before further statistical analysis.

Data analysis and statistics. Statistical analysis of the relationship between the measured protein levels and clinical features of the disease was conducted using the R statistical environment (27) and tidy verse set of packages (29). Repeated measures ANOVA was used for statistical comparisons in experiments with more than two groups. Dunnett's test was used for many-to-one group comparisons of MM melanoma samples to controls (30-32). The association between protein levels and Breslow index was evaluated using Kendall's tau correlation coefficient, and lines representing the Theil-Sen estimator of a linear relationship were used.

$\mathrm{t}$-Distributed stochastic neighbour embedding (t-SNE) implemented in the R Rtsne package was used for nonlinear dimension reduction, to visualise any possible patterns in the high-dimensional cytokine concentration data (33). Analyte levels below the level of detection (missing values) were replaced by $80 \%$ of the lower limit of detection of the assay. Data for each analyte were normalized relative to mean concentration overall data points (all time points in all patients and controls) for the given analyte. Rtsne was run with the initial principal component analysis step, perplexity 12 and $\theta$ parameter 0.5 over 8,000 iterations to reduce the dimensions to 2 .

Immunohistochemical analysis of paraffin sections of patient tumours and cultured cells, and microscopy. Tissue samples were fixed for 24-48 $\mathrm{h}$ in $4 \%$ neutral buffered formalin at room temperature and routinely processed to produce paraffin blocks. Sections $(2-\mu \mathrm{m}$-thick) were deparaffinised and rehydrated through xylene and $98 \%$ ethanol. Afterwards, the sections were washed in PBS, and heat-induced epitope retrieval was performed in citrate buffer, $\mathrm{pH} 6.0 \mathrm{in}$ an autoclave at $120^{\circ} \mathrm{C}$ for 3 min, with subsequent gradual cooling to room temperature for $60 \mathrm{~min}$. Non-specific binding of antibodies was inhibited using the Protein Block system (Dako; Agilent Technologies, Inc.; cat. no. X0909) followed by treatment with 3\% hydrogen peroxide (in PBS; Sigma-Aldrich; Merck KGaA) for 20 min at room temperature. Sections were incubated overnight at $4^{\circ} \mathrm{C}$ with biotinylated primary antibodies (manufacturer-validated summary antibody information in Table SI; the manufacturer validated all employed antibodies for use in these methods).

The following day, the sections were extensively washed and incubated with secondary (polymer horseradish peroxidase-tagged) antibody for $30 \mathrm{~min}$ at room temperature. 3-Amino-9-ethylcarbazol (AEC; DCS Innovative Diagnostik-Systeme) chromogen was used for visualisation of the immunohistochemical reaction, according to the manufacturer's protocol. Nuclei were counterstained with Gill's haematoxylin for $2 \mathrm{~min}$ at room temperature and mounted in Hydromount (National Diagnostics). Semi-quantitative analysis $(0$, negative; + , weakly positive; ++ , moderately positive; and +++, strongly positive) of the immunohistochemistry reaction was used to express the proportion of positive staining based on inspection under an optical microscope.

The cultured cells on coverslips were briefly fixed in $2 \%$ paraformaldehyde in PBS for 5 min at room temperature and permeabilised with Triton X-100 (Sigma-Aldrich; Merck KGaA). The coverslips with cultured cells were stained according to the same protocol using identical primary antibodies and other chemicals (with the omission of antigen retrieval). Imaging was performed with a Leica microscope DM2000 equipped with camera (DFC290 HD) and software package LAS, version 4.3.0 (Leica Microsystems GmbH): Magnification, $\mathrm{x} 400$; calibration, 1,000 pixels/pixel; capture format, 2,048x1,536; full frame; $\gamma=1.0$; gain, 1.0; auto exposure, on; nosepiece objective magnification, 40; mag changer magnification, 1 ; and aperture, 0.4 .

\section{Results}

Serological analysis. The present study analysed the levels of a 31-protein panel of cytokines, chemokines and growth factors in serum prepared from patients suffering from MM compared with healthy volunteers. Based on the initial hypothesis, these proteins were investigated for their ability to serve as biomarkers correlating with certain oncologically-important features of the disease. Among the analysed proteins, IL-5, IL-7 and GM-CSF were below the lower limit of detection in most of the samples and were excluded from further analyses. The levels of the remaining 28 proteins are summarised in Fig. 1 and Table SII. Data demonstrated that the levels of five studied proteins, namely IL-1RA, IL-2, IL-13, RANTES and G-CSF, were significantly different in the serum samples of healthy volunteers from the melanoma patients, according to Dunnett's test (Fig. 1). The results from the ANOVA summarised in Table SIII indicated that these five proteins were not significantly different in the serum samples of healthy volunteers compared with the melanoma patients.

It was observed that the Breslow values of primary tumours were significantly associated with the serum levels of four detected proteins, namely IL-6, IL-8, IL-13 and VEGF (Fig. 2).

The serum levels of IL-1RA, IL-13, IFN $\alpha$ and RANTES reflected the clinical stage of the disease at the time of MM diagnosis (Fig. 3). 

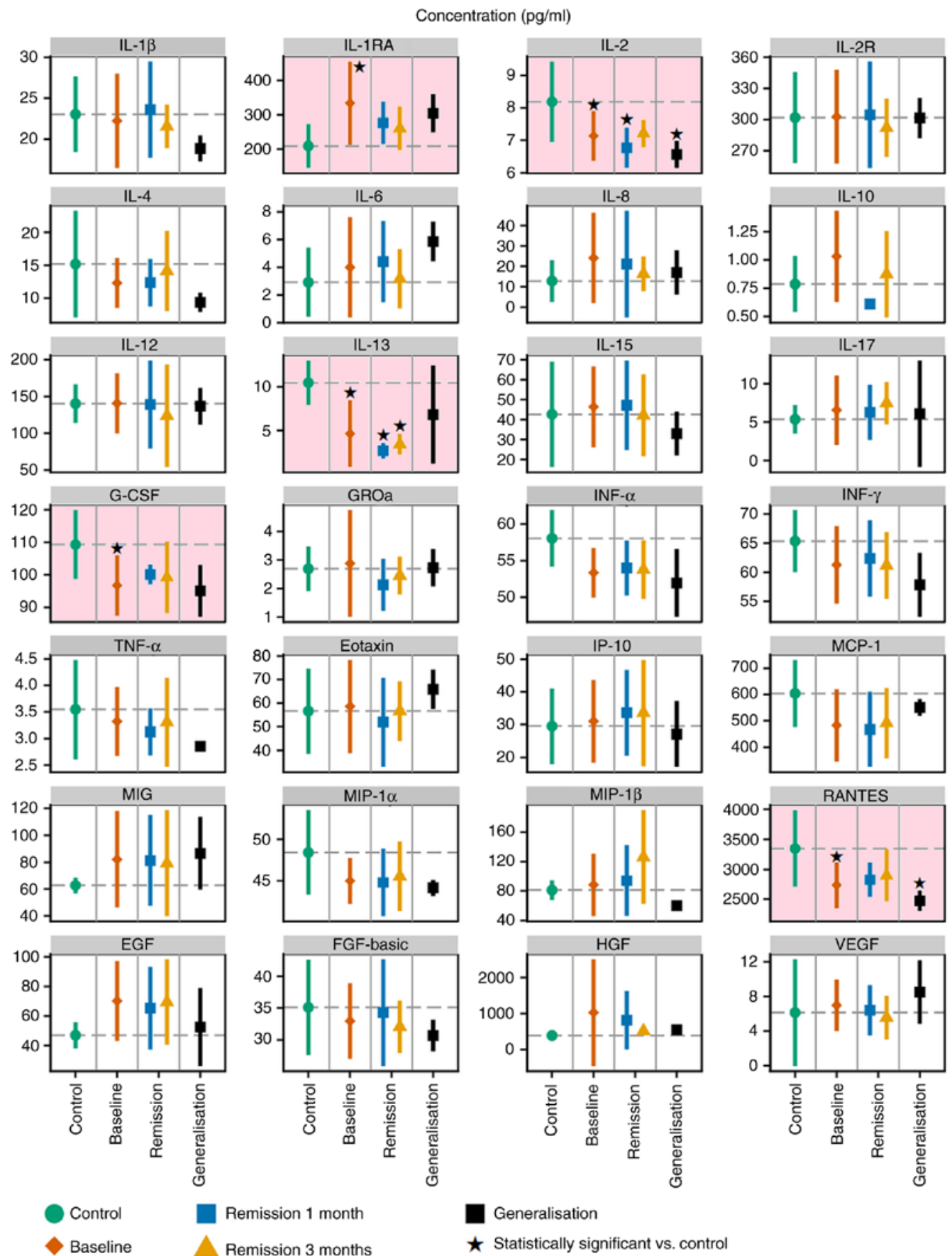

Remission 1 month

Generalisation

Statistically significant vs. control

Figure 1. Levels of 28 proteins in serum samples from healthy volunteers (control; green) and patients with MM. MM patient samples were collected at the time of diagnosis (baseline; red) and again 1 month and 3 months post-surgery. Data from the two later collections are plotted separately for subsets of patients without any evidence of disease (remission; blue, yellow) and patients at the stage of MM generalisation (progression, in black). The graphs represent the mean \pm SD. Statistical significance (Dunnett's one-to-many test with multiple testing correction) of comparisons between the control and patient subsets are highlighted with a pink background. * $<0.05$ vs. control. IL, interleukin; G-CSF, granulocyte-colony stimulating factor; IL-1RA, IL-1 receptor antagonist; IL-2R, IL-2 receptor; GROa, C-X-C motif chemokine ligand 1; IFN, interferon; TNF, tumor necrosis factor; MCP-1, C-C motif chemokine ligand 2; MIG, C-X-C motif chemokine ligand 9; IP-10, C-X-C motif chemokine ligand 10; MIP-1 $\alpha$, C-C motif chemokine ligand 3; MIP-1 $\beta$, C-C motif chemokine ligand 4; EGF, epidermal growth factor receptor; FGF-basic, basic fibroblast growth factor; HGF, hepatocyte growth factor; VEGF, vascular endothelial growth factor.

It is important to note that the cluster analysis demonstrated a vast extent of inter-individual differences among the tested patients and certain intra-individual level fluctuation (Fig. 4).

Analysis of primary MM lesions. To assess the contribution of the factors upregulated in MM patient sera to the MM microenvironment, immunohistochemistry of the tumours was performed in the same patients whose serum was analysed (Fig. 5). Immunohistochemical positivity for selected members of the studied protein families and their receptors in representative samples of primary tumours is illustrated in Fig. 5A-I and was quantified. Fig. 5J demonstrates the heterogeneity of primary tumours in the patients from whom the serum samples were collected. MM cells from all samples were positive for HGF, but the signal intensity 

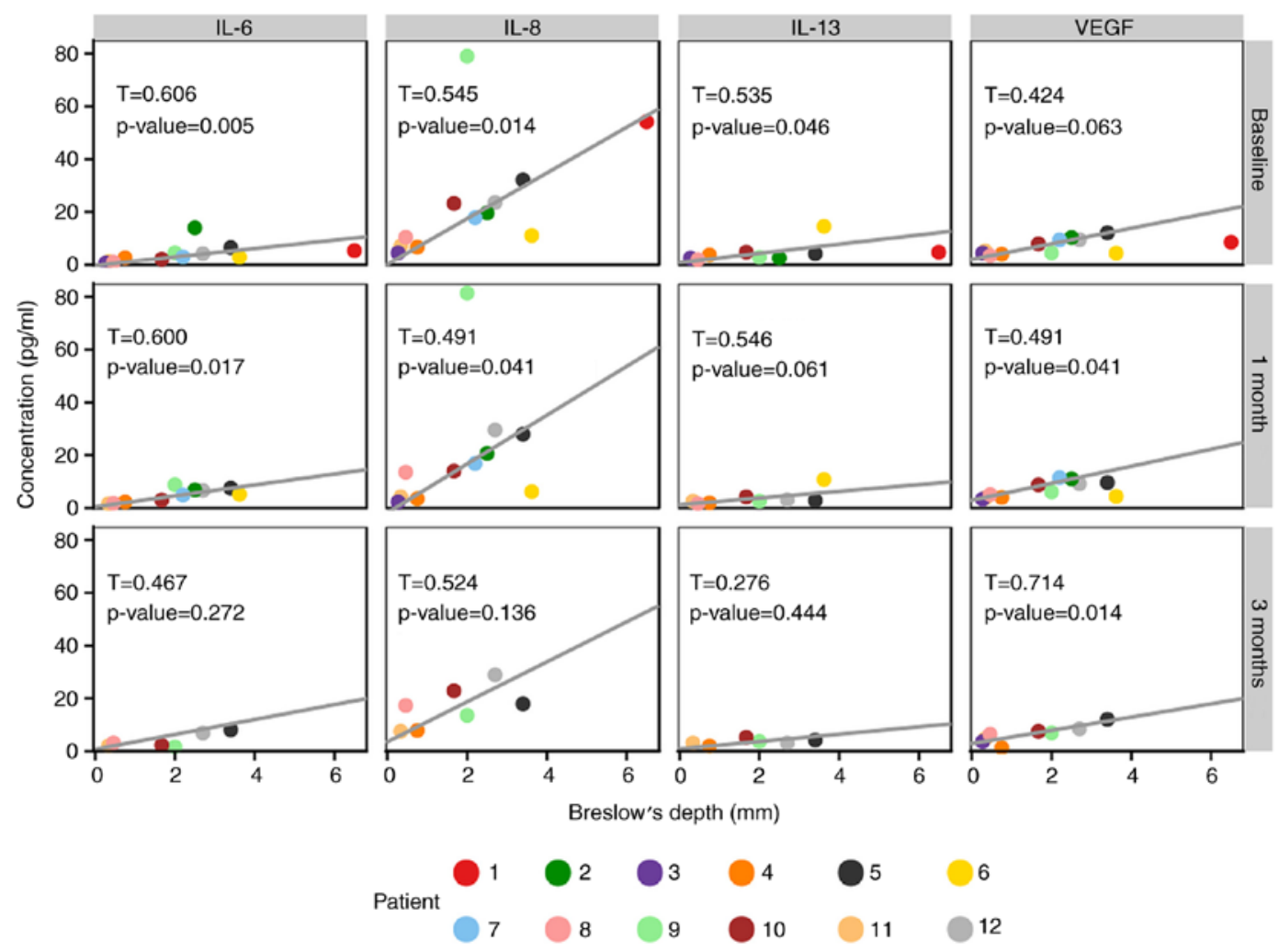

Figure 2. Correlation of Breslow values with serum levels of selected proteins. Scatterplots of values for individual MM patient at each sample collection point are presented. The lines represent the Theil-Sen estimator of a linear relationship. The non-parametric Kendall's tau correlation coefficient together with the corresponding P-value is displayed in each plot panel. IL, interleukin; VEGF, vascular endothelial growth factor.

was low. The studied tumours also widely expressed IL-6 and its receptor IL-6R, and VEGF-R1. The epidermis overlaying the MM lesions was highly positive for VEGF and VEGF-R2 in all studied samples (Fig. 5F). Macrophages widely expressed the studied markers, as demonstrated in the case of HGF (Fig. 5I).

Analysis of cultured MM cells (A2058, BLM and MP17), normal melanocytes (HP-Mel), normal dermal fibroblasts (HFP4) and CAFs (MAM and ZAM). The phenotype of melanoma cells and CAFs isolated from melanoma was analysed by studying the expression of selected factors detected in the serum of melanoma patients. The aim of this part of the study was to evaluate the production of these factors by isolated MM cells and CAFs. Data from cultured MM cells (A2058, BLM and MP17) demonstrated a similar phenotype to samples from primary MMs (Fig. 5) with several exceptions, such as high positivity for IL-8 (Fig. 6Ac, Bc and Cc) and VEGF-R2 (Fig. 6Ah, Bh and Ch). Normal melanocytes were negative for IL-6 (Fig. 6Da), IL-8 (Fig. 6Dc), CXCR1/2 (Fig. 6Dd and e), VEGF (Fig. 6Df), and the receptors VEGF-R1/R2 (Fig. 6Dg and h). As expected, these cells were highly positive for protein S100, MiTF and differentiation marker HMB45 (data not shown). Also as expected, both normal fibroblasts (HFP4) and fibroblasts isolated from the cutaneous metastases of MM (CAFs, similarly MAM or ZAM) exhibited a vimentin-rich cytoskeleton (data not shown). The signal for IL-6, IL-8, CXCR1, and CXCR2 was stronger in MM CAFs (Fig. 7Aa, c, d and e) than in normal fibroblasts (Fig. 7Ba, c, d and e).

\section{Discussion}

The present study demonstrated that the presence of a primary malignant melanoma tumour and its consequent metastatic spread is reflected by a profound change in inflammatory molecules in the serum. Similar findings for individual molecules or smaller groups have also been reported previously $(34,35)$.

Despite the observed broad inter-individual variability, the presence of a primary tumour was associated with significantly decreased levels of IL-2, IL-13, RANTES and G-CSF, and an increase in IL-1RA detected in the patient sera.

In detail, some of these factors also significantly differed in certain clinical stages of the disease, wherein IFN $\alpha$, IL-13 and RANTES were decreased significantly and IL-1RA was increased. The cohort of patients was also affected by the healing of the wound after surgery. However, no complicated courses of healing were observed in these 12 patients. An association between the Breslow index of the tumour and the serum levels of tested proteins was observed in the case of IL-6, IL-8, IL-13 and VEGF.

The low levels of IFN $\alpha$ in patients with melanoma seem to be important, because its anticancer effect has been well documented and recombinant IFN $\alpha$ is employed as a drug in cancer therapy, including adjuvant therapy for MM (36). Similar therapeutic implications are true for IL-2 (37).

Both downregulated interleukins IL-2 and IL-13 exhibit anticancer activity, with the potential for application in anticancer therapy (38-42).

RANTES is also well known as an essential inflammation-promoting chemokine. However, its role in anticancer 


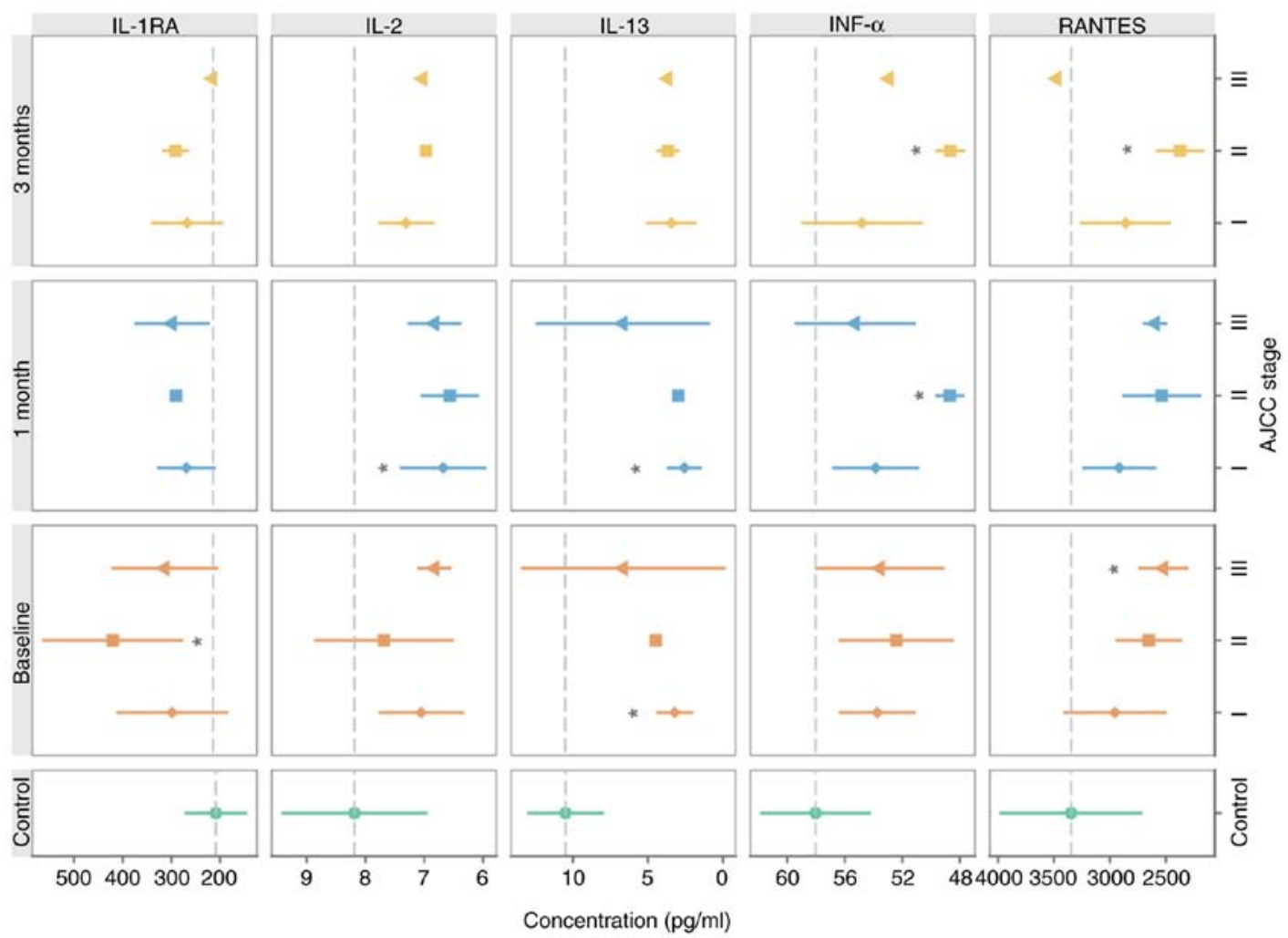

Figure 3. Relationship between selected serum proteins and clinical disease stage. Graphs represent the mean \pm SD. Statistical significance (Dunnett's one-to-many test with multiple testing correction) for comparisons between the control and particular disease stages are presented. ${ }^{*} \mathrm{P}<0.05$ vs. control. IL, interleukin; IL-1RA, IL-1 receptor antagonist; IFN, interferon.

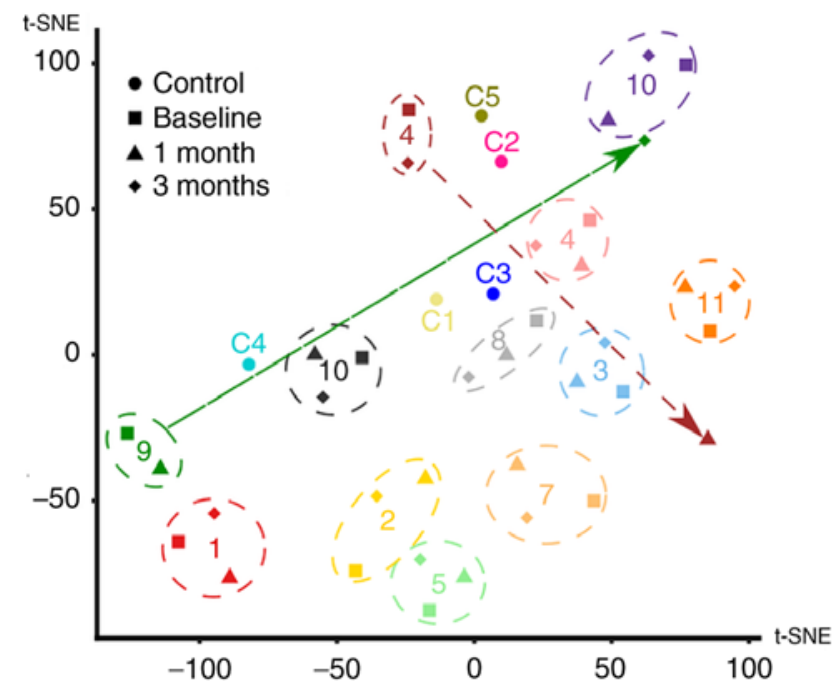

Figure 4. Cluster analysis of patients with MM. The high-dimensional dataset of 28 proteins measured for each patient was mapped onto a two-dimensional space using t-SNE. One data point for each of the controls (circles) and one data point for each patient/time-point combination (baseline, square; 1 month, triangle; 3 months, diamond) were plotted. Numbers (corresponding to Tables I and SII) were used to label the individual controls and patients. The overall variability of the dataset appeared to be mostly driven by individual differences between subjects, as data from different time points of the same patient generally clustered together (highlighted by the dashed circles) However, for a few patients, there were outlier data points (highlighted by arrows). tSNE, t-distributed stochastic neighbour embedding.

immunity/tumour facilitation requires to be further elucidated especially in melanoma $(43,44)$.
Attention should also be paid to the cytokine IL-6 and chemokine IL-8. Both molecules exhibit a broad tumour-supporting effect $(23,45)$. It should be noted that inflammation-supporting factors such as IL-6 and IL-8 are produced not only by MM cells and TILs, but are also provided in large quantities by CAFs $(23,25,46)$. This is apparent from the present immunohistochemical results. The contribution of particular components of a tumour can be easily documented through immunocytochemical analysis of isolated cell populations. Therefore, it may be expected that regardless of the actual cellular origin of these factors, the protein abundance will consequently be detected in the serum $(8,47-50)$. These facts highlight the importance of the tumour microenvironment and support the concept of cancer as a systemic disease $(6,51)$.

In general, IL-6 and IL-8 stimulate the metastatic spread of many tumours, including MM $(25,46,52)$, and participate in the induction of resistance to vemurafenib (18).

In the particular case of IL-6, its effect on MM seems to be stage-specific. IL-6 has an inhibitory effect in the initial stages of melanoma. However, IL-6 stimulates the growth and invasiveness of MM cells in advanced stages of the disease $(53,54)$. In general, blocking of IL-6 production seems to be beneficial for MM patients (55) because IL-6 stimulates cancer cachexia and wasting, a severe and terminal complication of malignant disease (56-59).

Chemokine IL-8 (CXCL8) and its receptors CXCR1 and CXCR2 play a notable role in melanoma pathogenesis, particularly in melanoma progression and metastasis (60). The serum concentration of IL- 8 can be correlated to the disease stage, and changes in the serum IL- 8 levels could be used to 

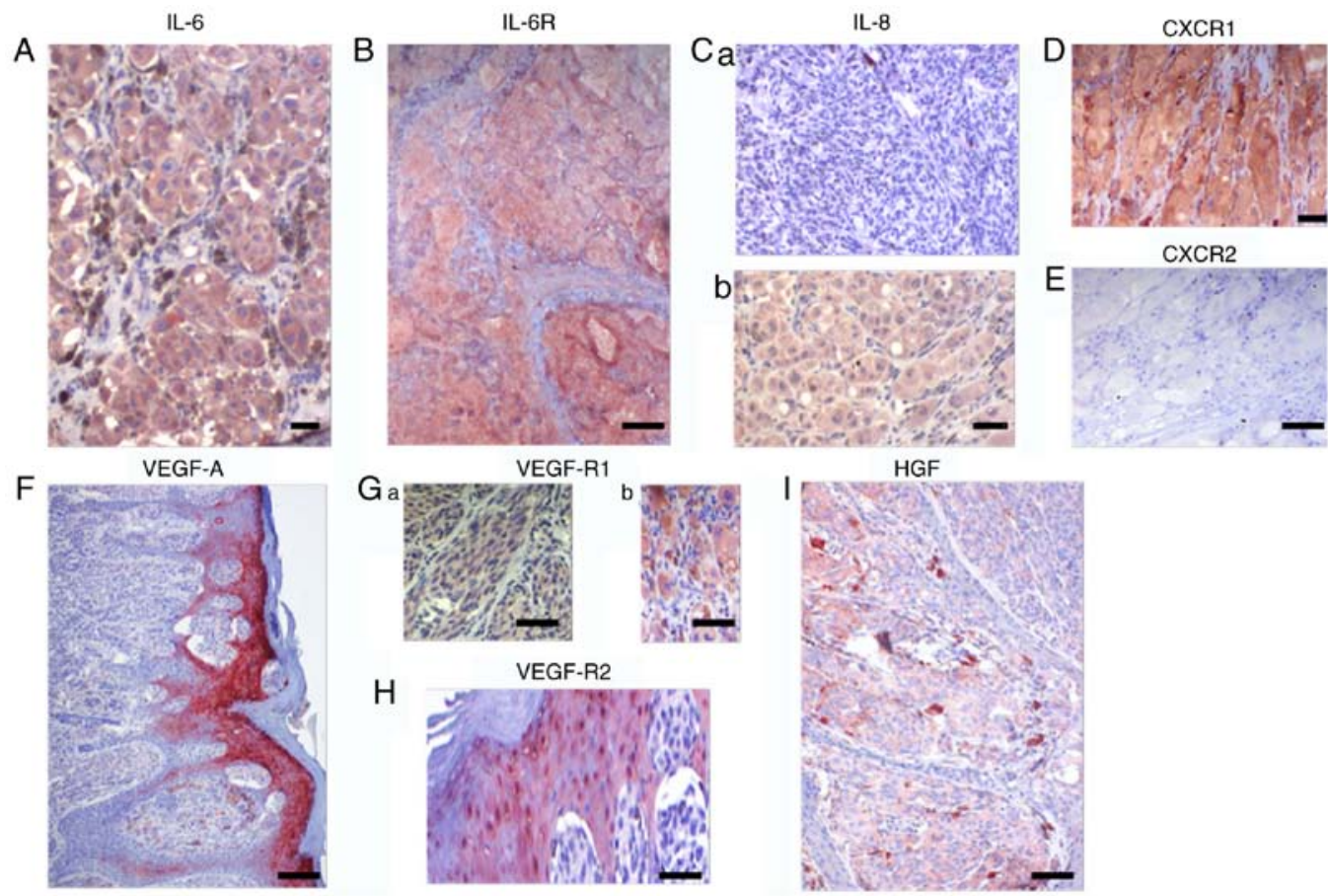

J
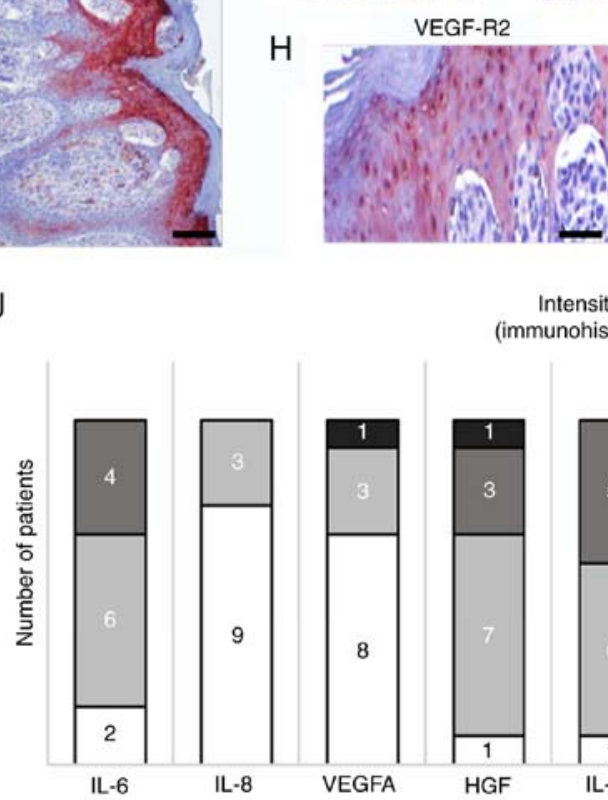

$$
\text { (immunohistochemistry) }
$$

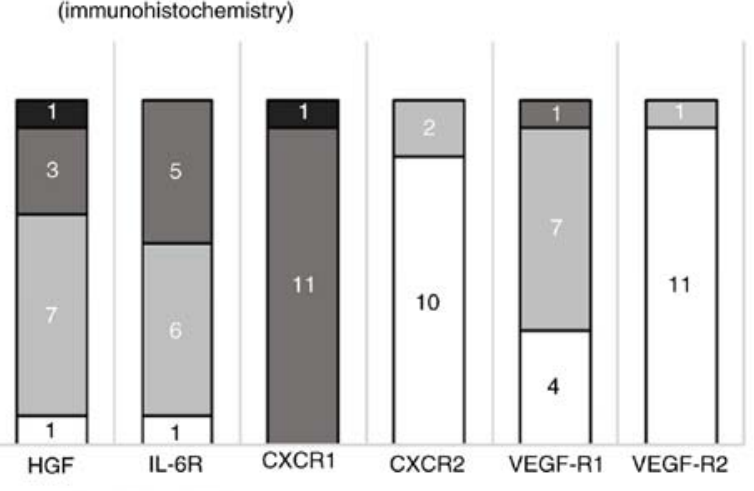

Figure 5. Characteristic samples of expression of selected protein markers in sections from primary MM in the same cohort of patients. Multiple markers were detected by immunohistochemistry in melanomas. (A) IL-6 and (B) IL-6 receptor were detected in the majority of tumours in MM cells. (C) IL-8 expression was highly variable in studied samples; representative sections are included. Differences in expression were also observed in CXCR1 and CXCR2. (D) CXCR1 with highly positive in all patients, which contrasted with (E) the low to negative CXCR2 expression. (F) Notable positivity for VEGF was observed in the epidermis overlaying the MM lesion. Expression of VEGF receptors (G) VEGF-R1 and (H) VEGF-R2 was also observed beside MM cells in the tumour microenvironment, represented by stromal macrophages and epidermis. (I) HGF was also observed in MM cells and macrophages. Scale bar, $50 \mu \mathrm{m}$. (J) A summary of the expression of selected markers in primary MM in the present cohort. Semi-quantitative analysis $(0,+,++$, and +++$)$ of the immunohistochemistry reaction was used to express the proportion of positive staining based on inspection under an optical microscope. The numbers of positive tumours are included on the graph. IL, interleukin; CXCR1, C-X-C motif chemokine receptor 1; HGF, hepatocyte growth factor; CXCR2, C-X-C motif chemokine receptor 2; VEGF, vascular endothelial growth factor; VEGF-AR1, VEGF-A receptor 1; VEGF-AR2, VEGF-A receptor 2; IL-6R, IL-6 receptor.

monitor and predict the clinical benefit of immune checkpoint inhibitor therapy (61).

In addition to the direct effect of IL-8 on cancer cells, this chemokine also stimulates the growth of capillaries in the tumour environment. Thus, it has a synergistic effect with VEGF (62). The correlation of serum levels of IL-8 with melanoma tumour mass has been previously described (63). Breslow's depth is generally accepted as a simple but precise prognostic factor. The present data demonstrated that the serum levels of IL-6 and IL-8 (both increased) reflect this tumour parameter.

It should be acknowledged here that surgical removal did not lead to an immediate lowering of the IL-6 and IL-8 levels.
It seems likely that a sustained level of these molecules may promote another source of this cytokine, other than from a tumour itself. This can be interpreted as evidence of the systemic proinflammatory environment in the patient.

The observation of an elevated serum level of VEGF in the samples from patients with MM is unsurprising, because its cancer-stimulating effect via the support of tumour vascularisation is well known (64). Serological elevation of VEGF is associated with melanoma progression and adverse immune effects, including elevation of $\mathrm{T}_{\mathrm{H}} 2$ cytokines (e.g., observed IL-10) and decreased of $\mathrm{T}_{\mathrm{H}} 1$ cytokines (e.g., observed IL-2 and interferon $\gamma$ ). These changes result in suppression of anti-tumour immunity $(65,66)$. 


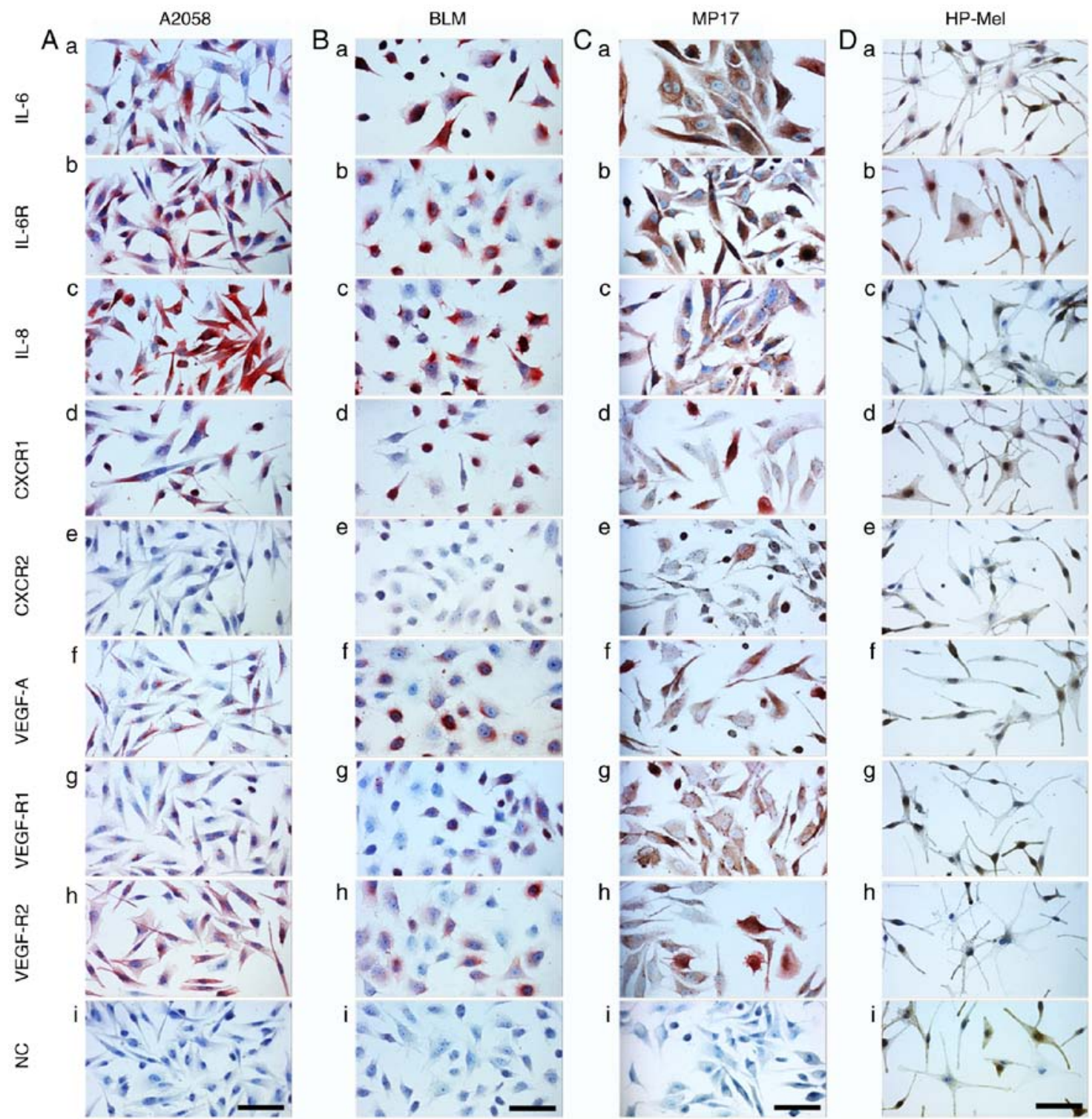

Figure 6. Detection of selected markers in MM cell lines. The detection was performed in (A) A2058, (B) BLM and (C) MP17 cells, and in (D) normal HP-Mel cells. HP-Mel are more pigmented than MM cell lines and their $\mathrm{H}_{2} \mathrm{O}_{2}$ bleaching was not as successful. Therefore, AEC substrate (red) was used for the immunocytochemical reaction detection. Generally, it was possible to note that positive staining of HP-Mel was negligible in comparison with that of MM cell lines. A positive signal for IL-6 and IL-6R was observed in HP-Mel cells. Scale bar, $100 \mu \mathrm{m}$. CXCR1, C-X-C motif chemokine receptor 1; CXCR2, C-X-C motif chemokine receptor 2; VEGF, vascular endothelial growth factor; VEGF-AR1, VEGF-A receptor 1; VEGF-AR2, VEGF-A receptor 2; IL-6R, IL-6 receptor; NC, normal control; HP-Mel, highly pigmented melanocyte.

Expression of CD114, a surface receptor for VEGF, has been described in association with melanoma progression (67), and it can be considered as a new marker for cancer cells originated from neural crest-derived stem cells (68).

Besides this, we observed significantly lower levels of G-CSF. G-CSF is known to stimulate formation of granulocytes, and its reduction related to cancer progression is therefore likely. Neutrophils are functionally plastic in the tumour microenvironment, and $\mathrm{N} 1 / \mathrm{N} 2$ functional polarisation has recently been accepted. Classically activated (N1) neutrophils inhibit metastatic growth. In contrast, alternatively polarised (N2) neutrophils have been reported to facilitate colonisation of the target organ by metastasis-initiating cancer cells.

Comparative analysis of serum samples with immunohistochemical findings in primary tumours and cultured cells has shown that both MM cells and cells forming the tumour microenvironment (CAFs, TILs, keratinocytes, macrophages and pericytes) participate in the changes of serum proteins. Distinct clinical stages of MM can induce a specific pattern of serum proteins that underlines the systemic effect of the disease (18).

Immunosuppressive properties of the melanoma microenvironment are responsible for the chronic inflammatory status of the organism, thus supporting the hypothesis of cancer as a systemic disease from an early stage. However, it does not solve the question of the cause and the consequence.

Immunohistochemical analysis of IL-6, IL-8, VEGF and their receptors was performed in primary melanomas as well as in several MM cell lines and CAFs. The resulting data harmonised with the analysis of patient sera. This further demonstrated that the MM cells and stromal cells (CAFs) participated in the production of the studied factors. On the other hand, data from individual patients are highly variable, which is supported by similar evidence 


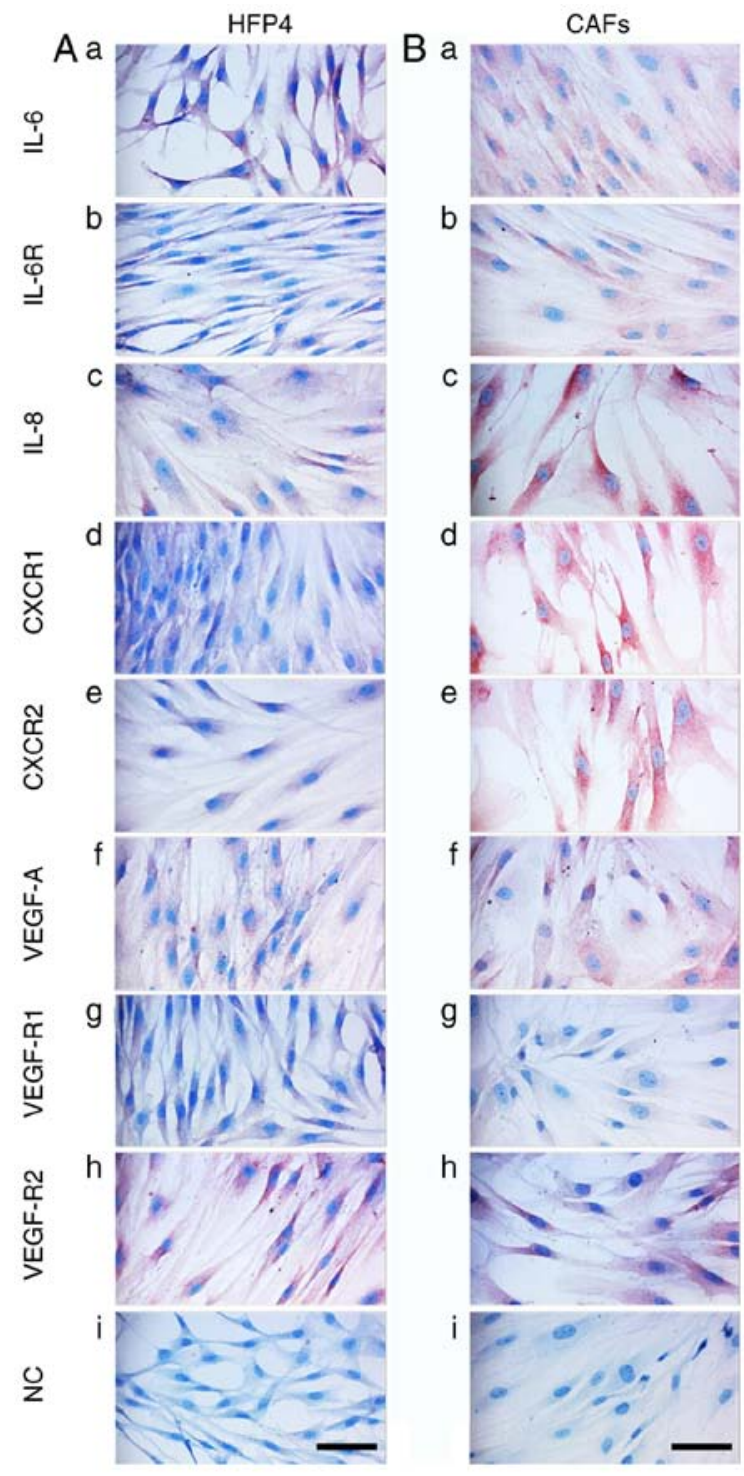

Figure 7. Detection of selected markers in normal HFP4 fibroblasts and CAFs isolated from a melanoma skin metastasis. Selected markers are visualised in primary culture of (A) normal dermal fibroblasts (HFP4) and (B) CAFs isolated from MM (MAM; ZAM data not shown). All types of fibroblasts expressed vimentin (data not shown). CAFs expressed more CXCR1 and CXCR2 than was observed in the normal fibroblasts (HFP4). Scale bar, $100 \mu \mathrm{m}$. CAFs, cancer-associated fibroblasts; CXCR1, C-X-C motif chemokine receptor 1; CXCR2, C-X-C motif chemokine receptor 2; VEGF, vascular endothelial growth factor; VEGF-AR1, VEGF-A receptor 1 VEGF-AR2, VEGF-A receptor 2; IL-6R, IL-6 receptor; NC, normal control.

in The Human Protein Atlas (Expression of VEGF, CXCL8, and IL-6, 2019; https://www.proteinatlas.org/ENSG00000112715VEGFA/pathology; https://www.proteinatlas.org/ ENSG00000169429-CXCL8/pathology; https://www.proteinatlas.org/ENSG00000136244-IL6/pathology). Therefore, a combination of more entries rather than a single biomarker seems to be necessary. Depression of serum levels of IL-2 and G-CSF in the serum of melanoma patients seems to have some therapeutic relevance because their participation in anticancer immunity was established and they were proposed for anticancer therapy (69).

In conclusion, the aforementioned analysis of the serum levels of growth factors VEGF and G-CSF, cytokines IL-6, IL-2, IL-1RA and IFN $\alpha$, and chemokines IL-8 and RANTES reflect various aspects of tumour biology in malignant melanoma. It is necessary to acknowledge that the currently used markers, such as LDH and S100 proteins, have staging and prognostic significance, but do not reflect the exact immunopathological actions of the organism at the time of melanoma diagnosis or during the disease progression $(6,51)$. Our data also indicated the apparent deregulation of the anti-tumour immune response, which is an essential factor for cancer progression. This sustained proinflammatory environment can significantly contribute to the clinically important phenomenon of long-lasting minimal residual disease. As noted earlier, due to the great inter-individual variability observed by us and by others, strategies based on a combination of several biomarkers or even multiplexing would be beneficial in the future. This approach can contribute to more effective therapy selection, and thus increase the therapeutic outcomes and the patient survival. This pilot study used a limited cohort of patients. Broader studies for validation of our observations are expected in the future. The present study focused on the soluble molecules detectable in human serum, and those that were significantly changed after processing using Dunnett's test. According to the ANOVA, no significant changes were observed between the control and the studied melanoma patients. This testing would require a much larger group of patients, which is planned in a continuation of this experiment. No significant changes were identified in proteins responsible for coping with oxidative stress in this study. However, there is well-established evidence that soluble molecules identified by us (e.g. IL-6) and their signalling pathways have a tight link to oxidative stress in tissues. The role of oxidative stress under pathological conditions, including in cancer biology, has been clearly established (70-72). The search for these proteins will represent the next step of our study.

\section{Acknowledgements}

Not applicable.

\section{Funding}

The manuscript represents the outcome of the project 'Centre for Tumour Ecology-Research of the Cancer Microenvironment Supporting Cancer Growth and Spread' (reg. no. CZ.02.1. 01/0.0/0.0/16_019/0000785) supported by the Research, Development and Education Operational Programme. This publication is also the result of the implementation of the project: 'The equipment for metabolomic and cell analyses' (reg. no. CZ.1.05/ 2.1.00/19.0400), supported by the Research and Development for Innovations Operational Programme (RDIOP) co-financed by the European Regional Development Fund and the state budget of the Czech Republic. This study was supported by the Grant Agency of the Czech Republic (project no. 16-05534S), Ministry of Health of the Czech Republic (project nos. 16-29032A and 16-30954A), Charles University project PROGRESS Q 28, and by the Ministry of Education, Youth and Sports of CR within the National Sustainability Programme I (no. LO1609) and II (Project BIOCEV-FAR; reg. no. LQ1604), and by project BIOCEV (no. CZ.1.05/1.1.00/02.0109).

\section{Availability of data and materials}

The datasets used during the present study are available from the corresponding author upon reasonable request. 


\section{Authors' contributions}

KSJ, LL and OK wrote the manuscript. KSJ was also head of the conception of the study. JK and PV performed the statistical analysis. JK, OK, IK and JS collected the patient samples, and HK, HKS and JM performed the proteomic analysis. LL, OK and PD conducted the histological and immunohistochemical analysis. KS, BD and LL performed the cell culture and immunocytochemistry analysis. All authors read and approved the final manuscript and agree to be accountable for all aspects of the research, in ensuring that the accuracy or integrity of any part of the work are appropriately investigated and resolved.

\section{Ethics approval and consent to participate}

The study was approved by the local ethics committee (Ethics Committee of the General University Hospital, Prague; no. 15/15). All tissue and blood samples were obtained strictly with the explicit informed consent of participants of the study.

\section{Patient consent for publication}

Not applicable.

\section{Competing interests}

The authors declare that they have no competing interests.

\section{References}

1. Global Burden of Disease Cancer Collaboration; Fitzmaurice C, Akinyemiju TF, Al Lami FH, Alam T, Alizadeh-Navaei R, Allen C, Alsharif U, Alvis-Guzman N, Amini E, et al: Global, regional, and national cancer incidence, mortality, years of life lost, years lived with disability, and disability-adjusted life-years for 29 cancer groups, 1990 to 2016: A systematic analysis for the global burden of disease study. JAMA Oncol 4: 1553-1568, 2018.

2. Schadendorf D, van Akkooi ACJ, Berking C, Griewank KG, Gutzmer R, Hauschild A, Stang A, Roesch A and Ugurel S: Melanoma. Lancet 392: 971-984, 2018.

3. Verma V, Sprave T, Haque W, Simone CB II, Chang JY, Welsh JW and Thomas CR Jr: A systematic review of the cost and cost-effectiveness studies of immune checkpoint inhibitors. J Immunother Cancer 6: 128, 2018.

4. Zhang M, Yang J, Hua W, Li Z, Xu Z and Qian Q: Monitoring checkpoint inhibitors: Predictive biomarkers in immunotherapy. Front Med 13: 32-44, 2019.

5. Breslow A: Thickness, cross-sectional areas and depth of invasion in the prognosis of cutaneous melanoma. Ann Surg 172: 902-908, 1970

6. Gershenwald JE, Scolyer RA, Hess KR, Sondak VK, Long GV, Ross MI, Lazar AJ, Faries MB, Kirkwood JM, McArthur GA, et al: Melanoma staging: Evidence-based changes in the American Joint Committee on Cancer eighth edition cancer staging manual. CA Cancer J Clin 67: 472-492, 2017.

7. Amann VC, Ramelyte E, Thurneysen S, Pitocco R, Bentele-Jaberg N, Goldinger SM, Dummer R and Mangana J Developments in targeted therapy in melanoma. Eur J Surg Oncol 43: 581-593, 2017.

8. Karagiannis P, Fittall $\mathrm{M}$ and Karagiannis SN: Evaluating biomarkers in melanoma. Front Oncol 4: 383, 2015.

9. Jurisic V, Radenkovic S and Konjevic G: The actual role of LDH as tumor marker, biochemical and clinical aspects. Adv Exp Med Biol 867: 115-124, 2015.

10. Gebhardt $\mathrm{C}$, Lichtenberger R and Utikal J: Biomarker value and pitfalls of serum S100B in the follow-up of high-risk melanoma patients. J Dtsch Dermatol Ges 14: 158-164, 2016.
11. Dummer R, Hauschild A, Lindenblatt N, Pentheroudakis G and Keilholz U; ESMO Guidelines Committee: Cutaneous melanoma: ESMO clinical practice guidelines for diagnosis, treatment and follow-up. Ann Oncol 26 (Suppl 5): v126-v132, 2015.

12. Dummer R, Siano M, Hunger R, Lindenblatt N, Braun R, Michielin O, Mihic-Probst D, von Moos R, Najafi Y, Guckenberger $\mathrm{M}$ and Arnold A: The updated Swiss guidelines 2016 for the treatment and follow-up of cutaneous melanoma. Swiss Med Wkly 146: 14279, 2016.

13. Pflugfelder A, Kochs C, Blum A, Capellaro M, Czeschik C, Dettenborn T, Dill D, Dippel E, Eigentler T, Feyer P, et al: Malignant melanoma S3-guideline 'diagnosis, therapy and follow-up of melanoma.' J Dtsch Dermatol Ges 11 (Suppl 6): S1-S126, 2013 (In English, German).

14. Paget S: The distribution of secondary growths in cancer of the breast. Lancet 1: 571-573, 1889.

15. Kareva I: What can ecology teach us about cancer? Transl Oncol 4: 266-270, 2011

16. Lacina L, Plzak J, Kodet O, Szabo P, Chovanec M, Dvorankova B and Smetana K Jr: Cancer microenvironment: What can we learn from the stem cell niche. Int J Mol Sci 16: 24094-24110, 2015.

17. Kodet O, Dvořánková B, Krejčí E, Szabo P, Dvořák P, Štork J, Krajsová I, Dundr P, Smetana K Jr and Lacina L: Cultivation-dependent plasticity of melanoma phenotype. Tumour Biol 34: 3345-3355, 2013.

18. Kodet O, Dvořánková B, Bendlova B, Sýkorová V, Krajsová I, Štork J, Kučera J, Szabo P, Strnad H, Kolář M, et al: Microenvironment-driven resistance to B-Raf inhibition in a melanoma patient is accompanied by broad changes of gene methylation and expression in distal fibroblasts. Int $\mathbf{J}$ Mol Med 41: 2687-2703, 2018.

19. Manzano JL, Layos L, Bugés C, de Los Llanos Gil M, Vila L, Martínez-Balibrea E and Martínez-Cardús A: Resistant mechanisms to BRAF inhibitors in melanoma. Ann Transl Med 4: 237, 2016.

20. Li YC, Zou JM, Luo C, Shu Y, Luo J, Qin J, Wang Y, Li D, Wang SS, Chi G, et al: Circulating tumor cells promote the metastatic colonization of disseminated carcinoma cells by inducing systemic inflammation. Oncotarget 8: 28418-28430, 2017.

21. Brouwer A, De Laere B, Peeters D, Peeters M, Salgado R, Dirix L and Van Laere S: Evaluation and consequences of heterogeneity in the circulating tumor cell compartment. Oncotarget 7: 48625-48643, 2016.

22. Mignogna C, Scali E, Camastra C, Presta I, Zeppa P, Barni T, Donato G, Bottoni $U$ and Di Vito A: Innate immunity in cutaneous melanoma. Clin Exp Dermatol 42: 243-250, 2017.

23. Kodet O, Lacina L, Krejčí E, Dvořánková B, Grim M, Štork J, Kodetová D, Vlček Č, Sáchová J, Kolář M, et al: Melanoma cells influence the differentiation pattern of human epidermal keratinocytes. Mol Cancer 14: 1, 2015.

24. Lacina L, Smetana K Jr, Dvoránková B, Pytlík R, Kideryová L, Kucerová L, Plzáková Z, Stork J, Gabius HJ and André S: Stromal fibroblasts from basal cell carcinoma affect phenotype of normal keratinocytes. Br J Dermatol 156: 819-829, 2007.

25. Jobe NP, Zivicová V, Mifková A, Rösel D, Dvořánková B, Kodet $\mathrm{O}$, Strnad H, Kolář M, Šedo A, Smetana K Jr, et al: Fibroblasts potentiate melanoma cells in vitro invasiveness induced by UV-irradiated keratinocytes. Histochem Cell Biol 149: 503-516, 2018.

26. Dvořánková B, Lacina L and Smetana K Jr: Isolation of normal fibroblasts and their cancer-associated counterparts (CAFs) for biomedical research. Methods Mol Biol 1879: 393-406, 2019.

27. R Core Team R: A Language and Environment for Statistical Computing 2017. https://www.R-project.org/.

28. Sanz H, Aponte JJ, Harezlak J, Dong Y, Ayestaran A, Nhabomba A, Mpina M, Maurin OR, Díez-Padrisa N, Aguilar R, et al: drLumi: An open-source package to manage data, calibrate, and conduct quality control of multiplex bead-based immunoassays data analysis. PLoS One 12: e0187901, 2017.

29. Colin B, Clifford S, Wu P, Rathmanner S and Mengersen K: Using boosted regression trees and remotely sensed data to drive decision-making. Open J Statistics 7: 859-875, 2017.

30. Dunnett CW: A multiple comparison procedure for comparing several treatments with a control. J Am Stat Assoc 50: 1096-1121, 1955.

31. Porshneva K, Papiernik D, Psurski M, Łupicka-Słowik A, Matkowski R, Ekiert M, Nowak M, Jarosz J, Banach J, Milczarek M, et al: Temporal inhibition of mouse mammary gland cancer metastasis by CORM-A1 and DETA/NO combination therapy. Theranostics 9: 3918-3939, 2019.

32. Schou IM and Marschner IC: Design of clinical trials involving multiple hypothesis tests with a common control. Biom J 59: 636-657, 2017. 
33. Rtsne: T-Distributed Stochastic Neighbor Embedding using a Barnes-Hut Implementation, https://cran.r-project.org/web/packages/Rtsne/index.html.

34. Muqaku B, Eisinger M, Meier SM, Tahir A, Pukrop T, Haferkamp S, Slany A, Reichle A and Gerner C: Multi-omics analysis of serum samples demonstrates reprogramming of organ functions via systemic calcium mobilization and platelet activation in metastatic melanoma. Mol Cell Proteomics 16: 86-99, 2017.

35. Weber JS, Sznol M, Sullivan RJ, Blackmon S, Boland G, Kluger HM, Halaban R, Bacchiocchi A, Ascierto PA, Capone M, et al: A serum protein signature associated with outcome after anti-PD-1 therapy in metastatic melanoma. Cancer Immunol Res 6: 79-86, 2018.

36. Ortiz A and Fuchs SY: Anti-metastatic functions of type 1 interferons: Foundation for the adjuvant therapy of cancer. Cytokine 89: 4-11, 2017.

37. Mizui M: Natural and modified IL-2 for the treatment of cancer and autoimmune diseases. Clin Immunol: Nov 8, 201. (Epub ahead of print). doi: 10.1016/j.clim.2018.11.002.

38. Arend WP: Interleukin 1 receptor antagonist. A new member of the interleukin 1 family. J Clin Invest 88: 1445-1451, 1991.

39. Ma HL, Whitters MJ, Jacobson BA, Donaldson DD, Collins M and Dunussi-Joannopoulos K: Tumor cells secreting IL-13 but not IL-13Ralpha2 fusion protein have reduced tumorigenicity in vivo. Int Immunol 16: 1009-1017, 2004.

40. Lavi G, Voronov E, Dinarello CA, Apte RN and Cohen S: Sustained delivery of IL-1 Ra from biodegradable microspheres reduces the number of murine B16 melanoma lung metastases. J Control Release 123: 123-130, 2007.

41. Alva A, Daniels GA, Wong MK, Kaufman HL, Morse MA, McDermott DF, Clark JI, Agarwala SS, Miletello G, Logan TF, et al: Contemporary experience with high-dose interleukin-2 therapy and impact on survival in patients with metastatic melanoma and metastatic renal cell carcinoma. Cancer Immunol Immunother 65: 1533-1544, 2016.

42. BuchbinderEI, Gunturi A,PerrittJ,DutcherJ, Aung S, Kaufman HL, Ernstoff MS, Miletello GP, Curti BD, Daniels GA, et al: A retrospective analysis of High-Dose Interleukin-2 (HD IL-2) following Ipilimumab in metastatic melanoma. J Immunother Cancer 4: 52, 2016.

43. Cambien B, Richard-Fiardo P, Karimdjee BF, Martini V, Ferrua B, Pitard B, Schmid-Antomarchi H and SchmidAlliana A: CCL5 neutralization restricts cancer growth and potentiates the targeting of PDGFR $\beta$ in colorectal carcinoma. PLoS One 6: e28842, 2011.

44. Aldinucci D and Colombatti A: The inflammatory chemokine CCL5 and cancer progression. Mediators Inflamm 2014: 292376, 2014.

45. Kolar M, Szabo P, Dvořánková B, Lacina L, Gabius HJ, Strnad H, Sáchová J, Vlček C, Plzák J, Chovanec M, et al: Upregulation of IL-6, IL-8 and CXCL-1 production in dermal fibroblasts by normal/malignant epithelial cells in vitro: Immunohistochemical and transcriptomic analyses. Biol Cell 104: 738-751, 2012.

46. Jobe NP, Rosel D, Dvořánková B, Kodet O, Lacina L, Mateu R, Smetana K and Brábek J: Simultaneous blocking of IL-6 and IL-8 is sufficient to fully inhibit CAF-induced human melanoma cell invasiveness. Histochem Cell Biol 146: 205-217, 2016.

47. Moretti S, Chiarugi A, Semplici F, Salvi A, De Giorgi V, Fabbri P and Mazzoli S: Serum imbalance of cytokines in melanoma patients. Melanoma Res 11: 395-399, 2001.

48. Guida M, Riccobon A, Biasco G, Ravaioli A, Casamassima A Freschi A, Palma MD, Galligioni E, Nortilli R, ChiarionSileni V, et al: Basal level and behaviour of cytokines in a randomized outpatient trial comparing chemotherapy and biochemotherapy in metastatic melanoma. Melanoma Res 16: 317-323, 2006

49. Yurkovetsky ZR, Kirkwood JM, Edington HD, Marrangoni AM, Velikokhatnaya L, Winans MT, Gorelik E and Lokshin AE: Multiplex analysis of serum cytokines in melanoma patients treated with interferon-alpha2b. Clin Cancer Res 13: 2422-2428, 2007.

50. Jiang H, Gebhardt C, Umansky L, Beckhove P, Schulze TJ, Utikal J and Umansky V: Elevated chronic inflammatory factors and myeloid-derived suppressor cells indicate poor prognosis in advanced melanoma patients. Int J Cancer 136: 2352-2360, 2015.

51. Mocellin S,Zavagno G and Nitti D: The prognostic value of serum S100B in patients with cutaneous melanoma: A meta-analysis. Int J Cancer 123: 2370-2376, 2008.

52. Jayatilaka H, Tyle P, Chen JJ, Kwak M, Ju J, Kim HJ, Lee JSH, Wu PH, Gilkes DM, Fan R and Wirtz D: Synergistic IL-6 and IL-8 paracrine signalling pathway infers a strategy to inhibit tumour cell migration. Nat Commun 8: 15584, 2017.
53. Lu C and Kerbel RS: Interleukin-6 undergoes transition from paracrine growth inhibitor to autocrine stimulator during human melanoma progression. J Cell Biol 120: 1281-1288, 1993.

54. Armstrong CA, Murray N, Kennedy M, Koppula SV, Tara D and Ansel JC: Melanoma-derived interleukin 6 inhibits in vivo melanoma growth. J Invest Dermatol 102: 278-284, 1994.

55. Uemura M, Trinh VA, Haymaker C, Jackson N, Kim DW, Allison JP, Sharma P, Vence L, Bernatchez C, Hwu P and Diab A: Selective inhibition of autoimmune exacerbation while preserving the anti-tumor clinical benefit using IL- 6 blockade in a patient with advanced melanoma and Crohn's disease: A case report. J Hematol Oncol 9: 81, 2016.

56. Narsale AA and Carson JA: Role of interleukin-6 in cachexia: Therapeutic implications. Curr Opin Support Palliat Care 8: 321-327, 2014.

57. Belizario JE, Fontes-Oliveira CC, Borges JP, Kashiabara JA and Vannier E: Skeletal muscle wasting and renewal: A pivotal role of myokine IL-6. Springerplus 5: 619, 2016.

58. Miller A, McLeod L, Alhayyani S, Szczepny A, Watkins DN, Chen W, Enriori P, Ferlin W, Ruwanpura S and Jenkins BJ: Blockade of the IL-6 trans-signalling/STAT3 axis suppresses cachexia in Kras-induced lung adenocarcinoma. Oncogene 36: 3059-3066, 2017.

59. Pettersen K, Andersen S, Degen S, Tadini V, Grosjean J, Hatakeyama S, Tesfahun AN, Moestue S, Kim J, Nonstad U, et al: Cancer cachexia associates with a systemic autophagy-inducing activity mimicked by cancer cell-derived IL-6 trans-signaling. Sci Rep 7: 2046, 2017.

60. Singh S, Singh AP, Sharma B, Owen LB and Singh RK: CXCL8 and its cognate receptors in melanoma progression and metastasis. Future Oncol 6: 111-116, 2010.

61. Sanmamed MF, Perez-Gracia JL, Schalper KA, Fusco JP, Gonzalez A, Rodriguez-Ruiz ME, Oñate C, Perez G, Alfaro C, Martín-Algarra S, et al: Changes in serum interleukin-8 (IL-8) levels reflect and predict response to anti-PD-1 treatment in melanoma and non-small-cell lung cancer patients. Ann Oncol 28: 1988-1995, 2017.

62. Gabellini C, Gómez-Abenza E, Ibáñez-Molero S, Tupone MG, Pérez-Oliva AB, de Oliveira S, Del Bufalo D and Mulero V: Interleukin 8 mediates bcl-xL-induced enhancement of human melanoma cell dissemination and angiogenesis in a zebrafish xenograft model. Int J Cancer 142: 584-596, 2018.

63. Sanmamed MF, Carranza-Rua O, Alfaro C, Oñate C, Martín-Algarra S, Perez G, Landazuri SF, Gonzalez A, Gross S, Rodriguez I, et al: Serum interleukin-8 reflects tumor burden and treatment response across malignancies of multiple tissue origins. Clin Cancer Res 20: 5697-5707, 2014.

64. Jayson GC, Kerbel R, Ellis LM and Harris AL: Antiangiogenic therapy in oncology: Current status and future directions. Lancet 388: 518-529, 2016.

65. Nevala WK, Vachon CM, Leontovich AA, Scott CG, Thompson MA and Markovic SN; Melanoma Study Group of the Mayo Clinic Cancer Center: Evidence of systemic Th2-driven chronic inflammation in patients with metastatic melanoma. Clin Cancer Res 15: 1931-1939, 2009.

66. Ohm JE, Gabrilovich DI, Sempowski GD, Kisseleva E, Parman KS, Nadaf S and Carbone DP: VEGF inhibits T-cell development and may contribute to tumor-induced immune suppression. Blood 101: 4878-4886, 2003.

67. Zhang L, Agarwal S, Shohet JM and Zage PE: CD114 expression mediates melanoma tumor cell growth and treatment resistance. Anticancer Res 35: 3787-3792, 2015.

68. Zage PE, Whittle SB and Shohet JM: CD114: A new member of the neural crest-derived cancer stem cell marker family. J Cell Biochem 118: 221-231, 2017.

69. Waldmann TA: Cytokines in cancer immunotherapy. Cold Spring Harb Perspect Biol 10: pii: a028472, 2018.

70. Kumari N, Dwarakanath BS, Das A and Bhatt AN: Role of interleukin-6 in cancer progression and therapeutic resistance. Tumour Biol 37: 11553-11572, 2016.

71. Elmarakby AA and Sullivan JC: Relationship between oxidative stress and inflammatory cytokines in diabetic nephropathy. Cardiovasc Ther 30: 49-59, 2012.

72. Vallée A and Lecarpentier Y: Crosstalk between peroxisome proliferator-activated receptor gamma and the canonical WNT/ $\beta$-catenin pathway in chronic inflammation and oxidative stress during carcinogenesis. Front Immunol 9: 745, 2018.

This work is licensed under a Creative Commons Attribution-NonCommercial-NoDerivatives 4.0 International (CC BY-NC-ND 4.0) License. 